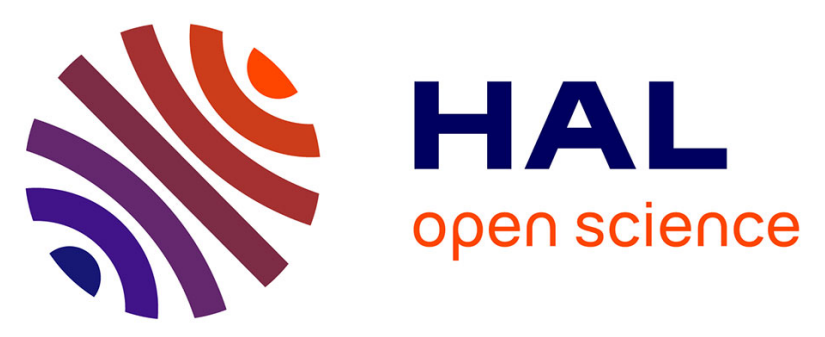

\title{
Dietary polyunsaturated fatty acids and heme iron induce oxidative stress biomarkers and a cancer promoting environment in the colon of rats
}

Françoise Guéraud, Sylviane Taché, J. P. Steghens, L. Milkovic, S. Borovic-Sunjic, N. Zarkovic, Eric Gaultier, Nathalie Naud, Cécile Héliès-Toussaint, F. Pierre, et al.

\section{To cite this version:}

Françoise Guéraud, Sylviane Taché, J. P. Steghens, L. Milkovic, S. Borovic-Sunjic, et al.. Dietary polyunsaturated fatty acids and heme iron induce oxidative stress biomarkers and a cancer promoting environment in the colon of rats. Free Radical Biology and Medicine, 2015, 83, pp.192-200. 10.1016/j.freeradbiomed.2015.02.023 . hal-01850558

\section{HAL Id: hal-01850558 https://hal.science/hal-01850558}

Submitted on 28 May 2020

HAL is a multi-disciplinary open access archive for the deposit and dissemination of scientific research documents, whether they are published or not. The documents may come from teaching and research institutions in France or abroad, or from public or private research centers.
L'archive ouverte pluridisciplinaire HAL, est destinée au dépôt et à la diffusion de documents scientifiques de niveau recherche, publiés ou non, émanant des établissements d'enseignement et de recherche français ou étrangers, des laboratoires publics ou privés. 
Original Contribution

\title{
Dietary polyunsaturated fatty acids and heme iron induce oxidative stress biomarkers and a cancer promoting environment in the colon of rats
}

\author{
Françoise Guéraud ${ }^{\mathrm{a}, *}$, Sylviane Taché ${ }^{\mathrm{a}}$, Jean-Paul Steghens ${ }^{\mathrm{b}}$, Lidija Milkovic ${ }^{\mathrm{c}}$, \\ Suzana Borovic-Sunjic ${ }^{c}$, Neven Zarkovic ${ }^{c}$, Eric Gaultier ${ }^{d}$, Nathalie Naud ${ }^{a}$, \\ Cécile Héliès-Toussaint ${ }^{a}$, Fabrice Pierre ${ }^{a}$, Nathalie Priymenko ${ }^{a}$ \\ a UMR 1331 Toxalim, INRA, INP, UPS, Team 9 "Prevention, Promotion of Carcinogenesis by Food," BP 93173, 180 chemin de Tournefeuille, \\ 31027 Toulouse Cedex, France \\ b CarMeN Unit, INSERM U1060/INRA 1235/University-Lyon1/INSA-Lyon, Team 3 “Glucolipotoxicity, Metabolic Stress and Diabetes," Faculté de Médecine Lyon \\ Sud, BP 12, 165 Chemin du Grand Revoyet, 69921 Oullins Cedex, France \\ ${ }^{\mathrm{c}}$ Rudjer Boskovic Institute, Laboratory for Oxidative Stress, Bijenicka 54, HR-10000 Zagreb, Croatia \\ 'UMR 1331 Toxalim, INRA, INP, UPS, Team 4 "Neuro-Gastroenterology and Nutrition" and Team 11 "Intestinal Development, Xenobiotics and \\ ImmunoToxicology," BP 93173, 180 chemin de Tournefeuille, 31027 Toulouse Cedex, France
}

\section{A R T I C L E I N F O}

\section{Article history:}

Received 4 July 2014

Received in revised form

3 February 2015

Accepted 20 February 2015

Available online 3 March 2015

\section{Keywords:}

Lipid peroxidation

Biomarkers

4-Hydroxynonenal

Malondialdehyde

Colorectal cancer

Heme iron

Polyunsaturated fatty acids

\begin{abstract}
A B S T R A C T
The end products of polyunsaturated fatty acid (PUFA) peroxidation, such as malondialdehyde (MDA), 4-hydroxynonenal (HNE), and isoprostanes ( 8 -iso- $\mathrm{PGF}_{2 \alpha}$ ), are widely used as systemic lipid oxidation/oxidative stress biomarkers. However, some of these compounds have also a dietary origin. Thus, replacing dietary saturated fat by PUFAs would improve health but could also increase the formation of such compounds, especially in the case of a pro-oxidant/antioxidant imbalanced diet. Hence, the possible impact of dietary fatty acids and pro-oxidant compounds was studied in rats given diets allowing comparison of the effects of heme iron vs. ferric citrate and of $\omega$-6- vs. $\omega$-3-rich oil on the level of lipid peroxidation/oxidative stress biomarkers. Rats given a heme iron-rich diet without PUFA were used as controls. The results obtained have shown that MDA and the major urinary metabolite of HNE (the mercapturic acid of dihydroxynonane, DHN-MA) were highly dependent on the dietary factors tested, while 8 -iso- PGF $_{2 \alpha}$ was modestly but significantly affected. Intestinal inflammation and tissue fatty acid composition were checked in parallel and could only explain the differences we observed to a limited extent. Thus, the differences in biomarkers were attributed to the formation of lipid oxidation compounds in food or during digestion, their intestinal absorption, and their excretion into urine. Moreover, fecal extracts from the rats fed the heme iron or fish oil diets were highly toxic for immortalized mouse colon cells. Such toxicity can eventually lead to promotion of colorectal carcinogenesis, supporting the epidemiological findings between red meat intake and colorectal cancer risk.

Therefore, the analysis of these biomarkers of lipid peroxidation/oxidative stress in urine should be used with caution when dietary factors are not well controlled, while control of their possible dietary intake is needed also because of their pro-inflammatory, toxic, and even cocarcinogenic effects.
\end{abstract}

(c) 2015 Elsevier Inc. All rights reserved.

\section{Introduction}

Replacement of dietary saturated fat by polyunsaturated fatty acids (PUFAs), especially $\omega-3$ fatty acids, would improve health,

\footnotetext{
Abbreviations: DBI, double bond index; DHN-MA, 1,4-dihydroxynonane-mercapturic acid; EIA, enzyme immunoassay; FAME, fatty acid methyl ester; HNE, 4-hydroxynonenal; HNE-His, HNE-histidine protein adduct; MDA, malondialdehyde; MPO, myeloperoxidase; PUFA, polyunsaturated fatty acid; TBARS, thiobarbituric acid reactive substances

* Corresponding author.

E-mail address: fgueraud@toulouse.inra.fr (F. Guéraud).
}

particularly cardiovascular and cognitive functions [1]. However, PUFAs, particularly $\omega$-3 fatty acids with a high double bond index (DBI), are prone to oxidation by dietary oxidants like heme iron, giving rise to secondary lipid peroxidation compounds.

These lipid oxidation products and their metabolites can be assayed in blood, urine, and tissues as markers of endogenous lipid peroxidation/oxidative stress. For instance, malondialdehyde (MDA) comes from the oxidation of fatty acids bearing more than two methylene interrupted double bonds [2]. Urinary MDA has been used to reflect the lipid peroxidation occurring in vivo in the case of oxidative stress due to, for instance, $\mathrm{CCl}_{4}$ poisoning, vitamin E deficiency, or iron nitriloacetate administration [3]. 
In the same way, elevated levels are associated with hypertensive disorders of pregnancy [4], ageing [5], and with exposure to polycyclic aromatic hydrocarbons and particulate matters [6]. However, Draper's group pointed out that urinary MDA could be a useful indicator of endogenous lipid peroxidation only when peroxidation of dietary lipids is precluded [3], because precursors of MDA are also found in the diet. Kanner's group reported the increase of plasmatic MDA after a red meat-rich meal that can be prevented by coffee or red wine polyphenols $[7,8]$. The mercapturic acid of dihydroxynonane (DHN-MA) is the major urinary metabolite of 4-hydroxynonenal (HNE), an end product of $\omega-6$ fatty acids oxidative breakdown, which is a well-known bioactive marker of lipid peroxidation involved in cell growth regulation and signaling [9]. Thus DHN-MA has also been used as a marker of oxidative stress/lipid peroxidation in $\mathrm{BrCCl}_{3^{-}}$[10] or $\mathrm{CCl}_{4}$-treated rats [11] and in smokers with or without vitamin $C$ supplementation [12]. Rats given a diet containing heme iron and $\omega-6$ fatty acids, in the form of hemoglobin or red meat and safflower oil, excrete huge quantities of DHN-MA, indicating the formation of HNE in diet or during digestion $[13,14]$. HNE is present in food containing heme iron and PUFAs [15]. Another group reported an important formation of HNE in thermally oxidized oils or in food fried in these oils, but these studies did not report any measurement of HNE metabolite in urine of animals fed on diets made with those oils $[16,17]$.

In the early 1990s, the determination of isoprostanes marked a new era in the field of oxidative stress biomarkers. Their unique precursor is arachidonic acid, and their formation is believed to be independent of the lipid content of the diet [18]. They appear to be more specific of lipid peroxidation than MDA. As for MDA and urinary metabolites of HNE, their excretion increase under conditions of oxidative stress [10]. For these reasons, isoprostanes are still regarded now as gold standards of lipid peroxidation/oxidative stress biomarkers and are widely used for this purpose.

In addition, secondary lipid oxidation reactive aldehydes are cytotoxic and genotoxic compounds, while some of them, especially HNE, are known also as second messengers of free radicals $[1,2,19]$. Their presence in the diet could have a toxic effect, especially on the digestive tract, which is the first target of such dietary compounds. In a previous work, we had observed that, after initiation of colorectal carcinogenesis, animals -fed a heme iron and $\omega-6$ fatty acid-rich diet, presented more preneoplastic lesions in their colon than rats -fed a control diet without heme iron. These results demonstrate the promoting effect of heme iron on colorectal cancer in these animals $[20,21]$. The cytotoxic activity of the fecal extracts from those rats on immortalized, but not cancerous, mouse colon epithelial cells was much more important when rats were given a heme iron-rich diet than control diet. Moreover a heme iron-rich diet induced a selective selection of preneoplastic cells [22]. This could be related to the epidemiological link existing between red meat, containing an important concentration of heme iron, and colorectal cancer in humans.

In the present study, we have tested the effect of two edible oils, containing predominantly $\omega-3$ fatty acids for fish oil and $\omega-6$ fatty acids for safflower oil, combined with heme iron or ferric citrate, with different pro-oxidant properties, on MDA, DHN-MA, and 8 -iso-PGF ${ }_{2 \alpha}$ urinary excretion in rats, in order to study the impact of a "peroxidable" diet on oxidative stress biomarkers. We used in a control diet coconut hydrogenated oil containing no polyunsaturated fatty acids. Hemin was used in a concentration that is in the same range as the one used in studies representing a meat-based Western diet by our group [20] or by Van der Meer and co-workers $[23,24]$. In addition, the cytotoxic activity of the fecal extracts of rats given the diets was evaluated on two colon/ rectal cell lines.

\section{Materials and methods}

Unless specified elsewhere in this section, reagents were purchased from Sigma (Saint-Quentin-Fallavier, France).

\section{Animals and diets}

Four-week-old female Fisher 344 rats (6 rats/group) were purchased from Charles River. Animal care was in accordance with our local ethic committee (number TOXCOM/0006/FG). They were housed individually in plastic metabolic cages and allowed for a week of acclimatization to their cage and the acclimatization diet before the start of the experimental diets. The room was kept at a temperature of $22{ }^{\circ} \mathrm{C}$ on a $12 \mathrm{~h}$ light-dark cycle. Animals had free access to tap water and to their respective diet. Diets were given each day at the end of the afternoon in order to limit oxidation. Feces and urine were collected each day. Food consumption and rat weight were recorded at Days $0,1,2,3,4,7$, and 10 and at Day 17, when the animals were euthanized. Colon and liver were excised and placed in liquid nitrogen before being stored at $-80^{\circ} \mathrm{C}$.

The acclimatization and the five experimental diets were based on a modified AIN-76 diet prepared and formulated in a powdered form by UPAE (INRA, Jouy-en-Josas, France). All diets were low-calcium diets $(0.8 \mathrm{~g} / \mathrm{kg})$ and contained $5 \%$ of oil: either corn oil for acclimatization diet (MP Biomedicals 901414) or hydrogenated coconut oil (MP 901404), safflower oil (MP 102888), and Menhaden fish oil (MP 960120), for experimental diets. In addition, experimental diets contained either hemin $(0.94 \mathrm{~g} / \mathrm{kg})$ (Sigma H5533) or ferric citrate $(0.36 \mathrm{~g} / \mathrm{kg})$ (F6129) purchased from Sigma and had a similar content of iron $(80 \mathrm{mg} / \mathrm{kg})$. Major fatty acid composition of the oils used in the different diets is shown in Table 1.

\section{Oxidative stress biomarker assays}

Twenty-four hour urine was collected in plastic tubes placed on ice during collection. Tubes contained $1 \mathrm{ml}$ of $360 \mathrm{mM}$ ethanolic solution of butylated hydroxytoluene (BHT). Urine was stored at $-20^{\circ} \mathrm{C}$ until use.

\section{MDA determination}

Urinary MDA was measured after a derivatization procedure using diaminonaphtalene as previously described for HPLC-UV quantitation [25], except that the detection was carried out with a single quadrupole mass spectrometer in the positive electrospray ionization mode. This enables the introduction of phenyl-benzimidazole (PBI) as an internal standard. PBI, which has the same molecular weight as the MDA derivative, exhibited a very similar chromatographic and ionization behavior as the diazepinium of MDA. Measurements were made with a P4000 liquid chromatograph connected to an autosampler AS 3000 and a single quadrupole mass Navigator Aqua detector (Thermo

Table 1

Major fatty acid ( $>10 \%$ ) composition of the PUFA containing dietary oils.

\begin{tabular}{|c|c|c|c|c|c|c|c|}
\hline & $16: 0$ & $16: 1 n-9$ & $18: 1 n-9$ & $18: 2 \mathrm{n}-6$ & $20: 5 n-3$ & $\begin{array}{l}22: 6 \\
n-3\end{array}$ & DBI \\
\hline Corn oil & $11 \%$ & & $25 \%$ & $60 \%$ & & & 146 \\
\hline $\begin{array}{l}\text { Safflower } \\
\text { oil }\end{array}$ & & & $11-13 \%$ & $70-80 \%$ & & & 170 \\
\hline $\begin{array}{l}\text { Menhaden } \\
\text { fish oil* }\end{array}$ & $15 \%$ & $12 \%$ & $9 \%$ & & $16 \%$ & $11 \%$ & 244 \\
\hline
\end{tabular}

DBI (double bond index $-\%$ of each fatty acid $\times$ number of double bond). Hydrogenated coconut oil contained $98.4 \%$ of saturated fatty acids (mainly lauric acid), its DBI was 3.

* A total composition of $\omega-3$ and $\omega-6$ fatty acids in Menhaden fish oil was: $\omega-3$ : 32.15 and $\omega-6: 9 \%$. 
Finnigan) with a silica-based C18 UP3BioP2 column $(150 \times 2 \mathrm{~mm}$, $5 \mu \mathrm{m}$ ) (Interchim, Montluçon, France) held at $50{ }^{\circ} \mathrm{C}$. The injected sample volume was $5 \mu \mathrm{l}$ and the flow rate was $230 \mu \mathrm{l} / \mathrm{min}$. Analyses were performed following the mobile phase: $85 \%$ of ammonium acetate (final concentration: $5 \mathrm{mM}, \mathrm{pH} 1.8$ ), and $15 \%$ of methanol/ acetonitrile (50/50, v/v).

The chromatograms were recorded as a total ion current (TIC) and in a single ion monitoring (SIM) mode at $\mathrm{m} / \mathrm{z}\left(\mathrm{M}+\mathrm{H}^{+}\right)$ equaled to 183.2 and 195.2 for the diazepinium of acetaldehyde, MDA, and PBI, respectively.

\section{DHN-MA determination}

DHN-MA assay was performed as previously described [26] by competitive enzyme immunoassay (EIA), using DHN-MA linked acetylcholinesterase as tracer. Diluted urines (from $1 / 200$ to $1 / 20,000$ in phosphate buffer depending on the group) were assayed in duplicates. Detection was recorded at $414 \mathrm{~nm}$ using a plate reader (Thermo Labsystems, Cergy-Pontoise, France).

\section{8-iso- $P G F_{2 \alpha}$ determination}

The assay is based on competitive EIA $[27,28]$ with 8 -iso-PGF $2 \alpha^{-}$ linked acetylcholinesterase enzyme as tracer. Diluted urines (1/40 to $1 / 400$ in phosphate buffer) were assayed in duplicates. Detection was recorded at $414 \mathrm{~nm}$ too. Reagents for competitive EIA were purchased from Bertin Pharma (Montigny-le-Bretonneux, France).

\section{Hepatic fatty acid analysis}

Lipid extraction was carried as described by Folch et al. [29]. Around $1 \mathrm{~g}$ fresh liver samples was weighed and crushed using a Polytron in $25 \mathrm{ml}$ of methanol/chloroform $(1 / 2, \mathrm{v} / \mathrm{v})$ containing $0.02 \%(\mathrm{wt} / \mathrm{v})$ BHT. Aliquots were stored overnight at $4{ }^{\circ} \mathrm{C}$ before being filtered. Saline solution $(5 \mathrm{ml})$ was added to the filter extract, and then vortexed. After centrifugation for $20 \mathrm{~min}$ at $1200 \mathrm{~g}$, the chloroform phase was filtered and evaporated to dryness.

The fatty acid methyl esters (FAMEs) were prepared as followed: to $10 \mathrm{mg}$ of sample, $200 \mu \mathrm{l}$ of internal standard (4 mg C19:0/ml dichloromethane) and then $2 \mathrm{ml}$ of methanolic $\mathrm{NaOH}$ $0.5 \mathrm{M}$ were added and placed for $10 \mathrm{~min}$ at $90{ }^{\circ} \mathrm{C}$ and then cooled for $6 \mathrm{~min}$. Then $3 \mathrm{ml}$ acetylchloride $10 \%(\mathrm{v} / \mathrm{v})$ was added and the mix was placed for $10 \mathrm{~min}$ at $90{ }^{\circ} \mathrm{C}$ and cooled for $6 \mathrm{~min}$. Finally, $5 \mathrm{ml}$ water and $1.6 \mathrm{ml}$ hexane were added before tumbling and centrifuging for $10 \mathrm{~min}$ at $1200 \mathrm{~g}$.

FAMEs were separated and identified using a gas chromatograph (Agilent Technologies, Model 6890 N, Santa Clara, USA) equipped with a flame ionization detector and a CP Sil-88 capillary column, $100 \mathrm{~m} \times 0.25 \mathrm{~mm}$ i.d., $0.2 \mu \mathrm{m}$ film (Agilent Technologies, Middleburg, The Netherlands). The chromatographic conditions were as follows: injector temperature $255^{\circ} \mathrm{C}$ and detector temperatures $260{ }^{\circ} \mathrm{C}$; oven temperature with initial temperature at $60{ }^{\circ} \mathrm{C}$ for $2 \mathrm{~min}$, increased to $150{ }^{\circ} \mathrm{C}$ at $8{ }^{\circ} \mathrm{C} / \mathrm{min}$, held $12 \mathrm{~min}$, increased at $175^{\circ} \mathrm{C}$ at $2{ }^{\circ} \mathrm{C} / \mathrm{min}$, held $20 \mathrm{~min}$, increased at $225^{\circ} \mathrm{C}$ at $5{ }^{\circ} \mathrm{C} / \mathrm{min}$ held $10 \mathrm{~min}$, and increased at $240^{\circ} \mathrm{C}$ at $10^{\circ} \mathrm{C} / \mathrm{min}$ and held at $240{ }^{\circ} \mathrm{C}$ for $10 \mathrm{~min}$. Peaks were identified by comparison with authentic FAME standard (Larodan Fine Chemicals, Malmö, Sweden). Automated expression of data was performed with Peak Simple software (Version 3.28, SRI-Instruments Europe GmbH, Bad Honnef, Germany).

\section{Hepatic HNE-His protein adducts}

HNE-histidine (HNE-His) adducts were measured in homogenized tissues in phosphate buffered saline (PBS) according to Borovic et al. [30] for cultured cells, using a standard curve of
HNE-albumin adducts. Mouse monoclonal primary antibody was a generous gift from Dr. G. Waeg [31].

\section{Myeloperoxidase (MPO) assay}

MPO (EC 1.11.2.2.) activity, a marker of polymorphonuclear neutrophil primary granules, was measured in colonic tissues, according to the method of Bradley et al., slightly modified [32]. After euthanasia, a sample of colon was suspended in potassium

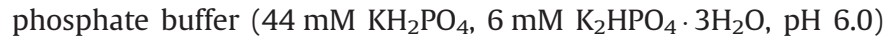
and homogenized on ice by using a Polytron. After 3 cycles of freezing and thawing, suspensions were centrifuged at $6000 \mathrm{~g}$ for $15 \mathrm{~min}$ at $4{ }^{\circ} \mathrm{C}$. Supernatant fractions were discarded and pellets were resuspended in hexadecyl trimethylammonium bromide buffer (HTAB $0.5 \%$, wt $/ \mathrm{v}$, in $50 \mathrm{mM}$ potassium phosphate buffer, $\mathrm{pH}$ 6.0), a detergent inducing the release of MPO from neutrophil primary granules. These suspensions were sonicated on ice and then centrifuged at $6000 \mathrm{~g}$ for $15 \mathrm{~min}$ at $4{ }^{\circ} \mathrm{C}$. Supernatants were assayed spectrophotometrically for MPO activity. Supernatant was diluted in potassium phosphate buffer $(\mathrm{pH}$ 6.0) containing $0.167 \mathrm{mg} / \mathrm{ml}$ of $\mathrm{O}$-dianisidine dihydrochloride and $0.0005 \% \mathrm{H}_{2} \mathrm{O}_{2}$. Changes in absorbance at $450 \mathrm{~nm}$ were recorded every $30 \mathrm{~s}$ over 2 min. One unit of MPO was defined as the quantity of MPO degrading $1 \mu \mathrm{mol} \mathrm{H}_{2} \mathrm{O}_{2} \min ^{-1} \mathrm{ml}^{-1}$ at $25^{\circ} \mathrm{C}$. Finally, MPO activity was expressed as units of MPO activity per gram of proteins (Units/g protein).

\section{C-reactive protein assay}

The C-reactive protein was measured in rat plasma, at Day 17, using the high-sensitivity CRP (PTX1) Rat ELISA Kit (ab108827, Abcam, Cambridge, UK) according to the manufacturer instructions.

\section{TBARS and viability assays}

\section{Fecal extract preparation for TBARS and cytotoxicity assay}

For TBARS (thiobarbituric acid reactive substances) assay and cytotoxic activity on epithelial cells, fecal waters were prepared from feces collected during $24 \mathrm{~h}$ in each metabolic cage, as described previously [21]. TBARS were measured in fecal water and in diet (left $24 \mathrm{~h}$ at room temperature to represent the maximal oxidation in diet) according to Ohkawa et al. [33], exactly as described previously [20].

\section{Cell culture and treatment}

We used cells obtained previously from an immortomouse [34] and the mouse rectum carcinoma CMT93 cell line (European Collection of Cell Cultures (ECACC)). Cells used for cytotoxicity assay of fecal water were seeded into 96-well culture plates at a seeding density of $3.2 \times 10^{4}$ and $1.6 \times 10^{4}$ cells per well in DMEM culture medium, for immortomouse deriving cells and CMT93 cells, respectively. The immortomouse deriving cells were cultured at $33{ }^{\circ} \mathrm{C}$ with interferon $\gamma$ until subconfluence, and transferred at $37{ }^{\circ} \mathrm{C}$ without interferon $\gamma$ for $24 \mathrm{~h}$. Under these conditions, they behave as primary cells. After $24 \mathrm{~h}$, these cells were at confluence. CMT93 cells were cultured for $48 \mathrm{~h}$. The culture medium was replaced with diluted and filtered $(0.2 \mu \mathrm{m})$ fecal water in DMEM culture medium (1/10 for all fecal waters). After adding fecal water, cells were incubated at $37{ }^{\circ} \mathrm{C}$ for another $24 \mathrm{~h}$. Analyses were done on fecal waters pooled by group, on 6 replicates.

\section{MTT assay}

Cells were then washed, $100 \mu$ l of MTT (3-(4,5-dimethylthiazol2-yl)-2,5-diphenyltetrazolium bromide) solution $(0.45 \mathrm{mg} / \mathrm{ml}$ in PBS) was added to each well and the cells were incubated at $37{ }^{\circ} \mathrm{C}$ 
for another $4 \mathrm{~h}$. The reaction product was solubilized in $100 \mu \mathrm{l}$ lysis buffer (SDS 10\%, $\mathrm{NaOH} 0.01 \mathrm{M}$ ) before the color of the reaction product was quantified using a plate reader at $570 \mathrm{~nm}$.

\section{Statistical analyses}

The effects of the different diets were analyzed using one-way ANOVA and Student's $t$ tests. Data were transformed into log to correct for unequal variance when necessary. Means were compared using Tukey's multiple comparisons test. Different letters between groups represent statistical differences with at least $P<0.05$. Statistics were performed using GraphPad Prism 6 software.

\section{Results}

\section{Body weight and food consumption}

Heme-containing diets, particularly the one with fish oil, were less accepted by the animals, probably because of their rancid odor, even though new food was given each day at the end of the afternoon (Fig. 1).

As a consequence, animals fed on those diets gained significantly less weight during the experimental period $(P=0.03$, at Day17).

\section{Urinary oxidative stress biomarkers}

Urinary MDA, DHN-MA, and iso- $\mathrm{PGF}_{2 \alpha}$ were measured at Day 0 , before the starting of the experimental diets, at Days 1 and 4 and at the end of the experimental period. Fig. 2 shows the results obtained at Day 17 and at Day 0 (end of the acclimatization period).

Urinary MDA levels were dependent on both dietary parameters: the type of oil used and the type of iron source. The most prominent effect was seen for fish oil, which had a 130- and a 30fold increase with heme iron and ferric citrate, compared to urine taken at Day 0 (acclimatization diet), respectively. Safflower oil had a less pronounced enhancing effect with only a 5-fold increase in the urinary excretion of MDA, when combined to heme iron. Heme iron induced a 5-fold increase in the urinary excretion of MDA when combined to fish and safflower oil, when compared with the corresponding ferric citrate diets. Interestingly, heme iron had no effect on MDA urinary excretion when combined to coconut oil. Besides, the significant effect of fish oil was also observed at Days 1 and 4 (data not shown).

For urinary DHN-MA, PUFA-rich oils and heme iron had an increasing effect but with a predominant effect of heme iron which increased the excretion by a 30 -fold and a 300 -fold factor for fish oil and safflower oil, respectively, when compared to urine taken at Day 0. An 8-fold and an 80-fold factor increase was obtained when heme effects were compared to the data obtained for the respective ferric citrate diets. When combined to ferric citrate, the two oils increased 4-fold the excretion of DHN-MA compared to urine taken at Day 0. It should be also noted that the most impressive factor of a 1000 -fold increase of urinary DHN-MA was observed on the Day 4 for a diet comprising safflower oil and heme iron (data not shown), compared to urine taken at Day 0, and the difference was also significant between Day 1 and Day 0 . Again, heme iron had no effect on DHN-MA urinary excretion when combined with the saturated coconut oil.

As expected, the diets had much less pronounced effects on 8 -iso-PGF ${ }_{2 \alpha}$ urinary excretion. However, significant differences were observed, notably with the presence of heme iron in diet that induced a 1.5-fold and a 5-fold increase with fish oil and safflower oil, respectively, when compared to the corresponding ferric citrate diets, while heme iron induced no increase when combined to coconut oil. A significant increase with heme iron and unsaturated oils was also observed at Days 1 and 4 .

As rats presented loose stools with heme iron and polyunsaturated fatty acid-containing diets, and to tentatively explain the increase in 8-iso- $\mathrm{PGF}_{2 \alpha}$ excretion by factors other than formation from dietary precursors, we measured MPO in colon tissue, as a marker of colonic inflammation (Fig. 3). We observed a significant increase in MPO activity with heme iron/PUFA diets compared to safflower oil combined to ferric citrate or to coconut oil/heme iron diets. However, this increase did not correlate with either 8-iso$\mathrm{PGF}_{2 \alpha}$ or to MDA and DHN-MA excretion. However, this supported the assumption of pro-inflammatory effects of the heme iron/PUFAcontaining diets, in particular if combined with fish oil. We also measured plasmatic C-reactive protein as a marker of inflammation but no differences were observed with the different diets (Fig. 4).

Because the most impressive differences of the urinary biomarkers of lipid peroxidation were observed for DHN-MA, which is the major urinary metabolite of $\mathrm{HNE}$, we measured by genuine ELISA the levels of HNE-His adducts in the liver of the rats fed on the different diets (Fig. 5). As can be seen, a moderate but significant HNE-increasing effect of the combination of safflower oil and heme iron was detected when compared to fish oil and ferric citrate diet, which was in agreement with the findings of the urinary DHN-MA determinations, although the increase observed on HNE-His was far less important (Fig. 2).

To evaluate further if the different diets could modify the fatty acid composition of rat tissues, and thereby influence the formation of the endogenous lipid peroxidation biomarkers, the percentages of the precursors of HNE ( $\omega-6$ fatty acids), 8 -iso-PGF $2 \alpha$ (arachidonic acid), and MDA (fatty acids with at least three double bonds) were evaluated in the liver (Table 2).

The urinary excretion of 8 -iso- $\mathrm{PGF}_{2 \alpha}$ roughly paralleled the presence of its precursor, arachidonic acid (20:4 n-6), in liver for hemin groups, while this was not the case for ferric citrate groups.
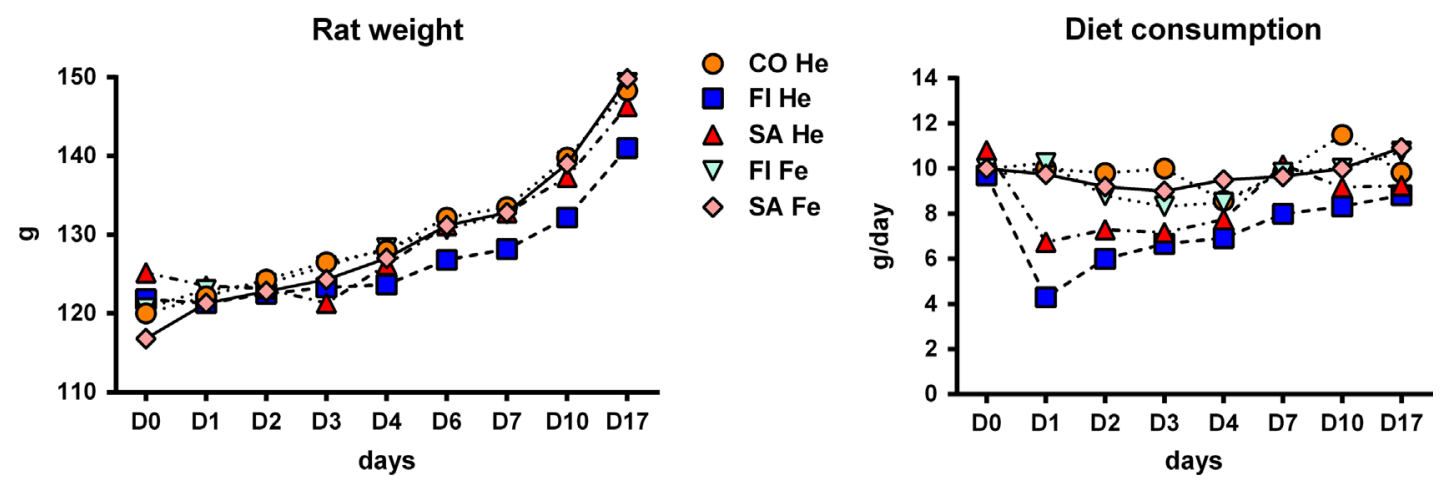

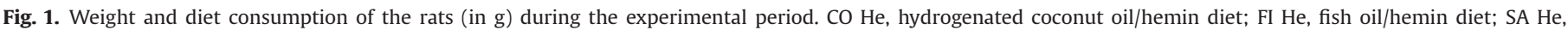
safflower/hemin diet; FI Fe; fish oil/ferric citrate diet; SA Fe; safflower/ferric citrate diet. $n=6$ animals. 
Urinary MDA

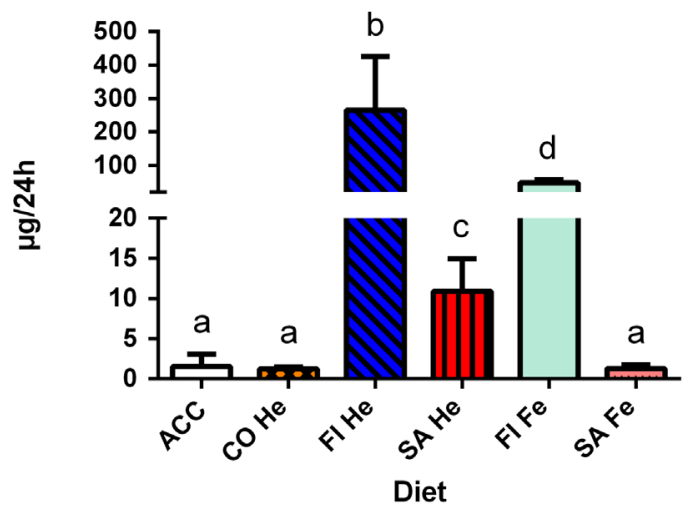

Urinary DHN-MA

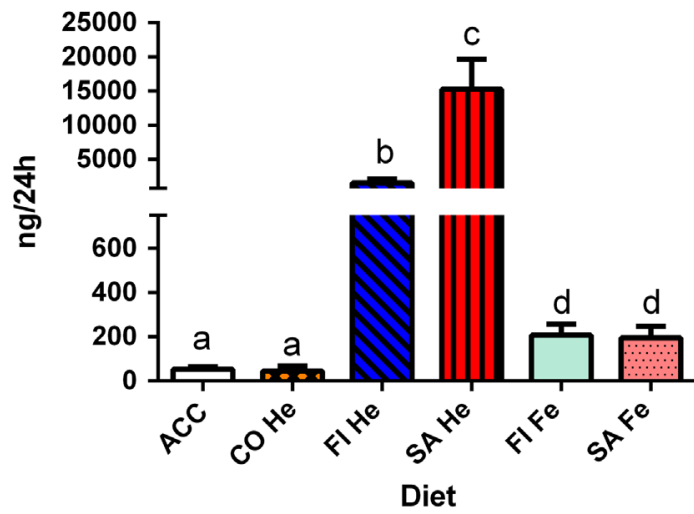

Urinary 8-iso-PGF $2 \alpha$

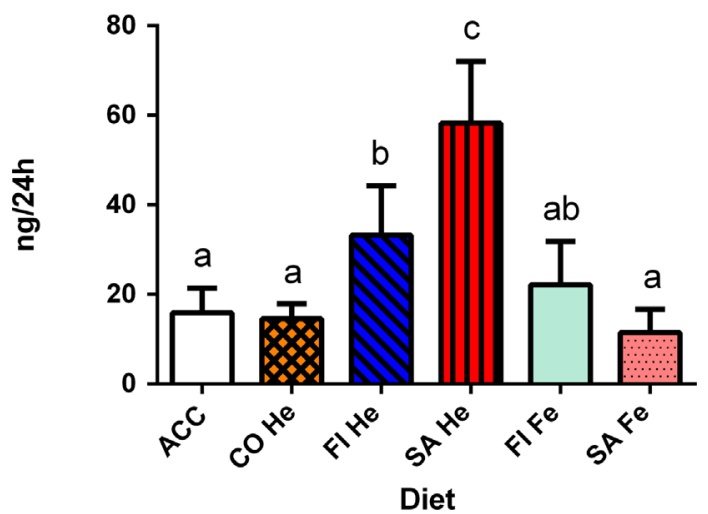

Fig. 2. Urinary excretion of three lipid oxidation products at Day 0 and at Day 17. ACC: urine taken before the start of the experimental diets at Day 0 (acclimatization diet). Experimental diets: $\mathrm{CO} \mathrm{He}$, hydrogenated coconut oil/hemin diet; FI He, fish oil/hemin diet; SA He, safflower/hemin diet; FI Fe; fish oil/ferric citrate diet; SA Fe; safflower/ferric citrate diet. Different letters between groups show significant statistical differences with at least $P<0.05 . n=6$ Animals.

On the other hand, the huge difference observed between hemin and ferric citrate groups for DHN-MA urinary excretion was not observed between these groups for $\omega-6$ fatty acid composition, although we observed more $\omega-6$ fatty acids (around $40 \%$ more) in hemin groups than in ferric citrate ones. A similar increasing effect of hemin was observed in safflower groups for $\omega-3$ fatty acids.

Finally, the differences between groups observed for MDA urinary excretion were not reflected by the composition of MDA precursors in the liver, or by the DBI.

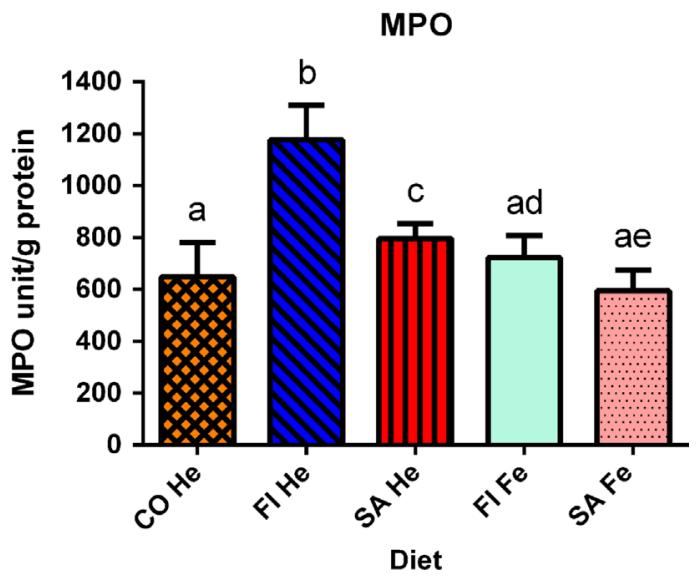

Fig. 3. Myeloperoxidase (MPO) activity in rat colon. $\mathrm{CO} \mathrm{He}$, hydrogenated coconut oil/hemin diet; FI He, fish oil/hemin diet; SA He, safflower/hemin diet; FI Fe; fish oil/ferric citrate diet; SA Fe; safflower/ferric citrate diet. Different letters between groups show significant statistical differences with at least $P<0.05 . n=6$ animals.

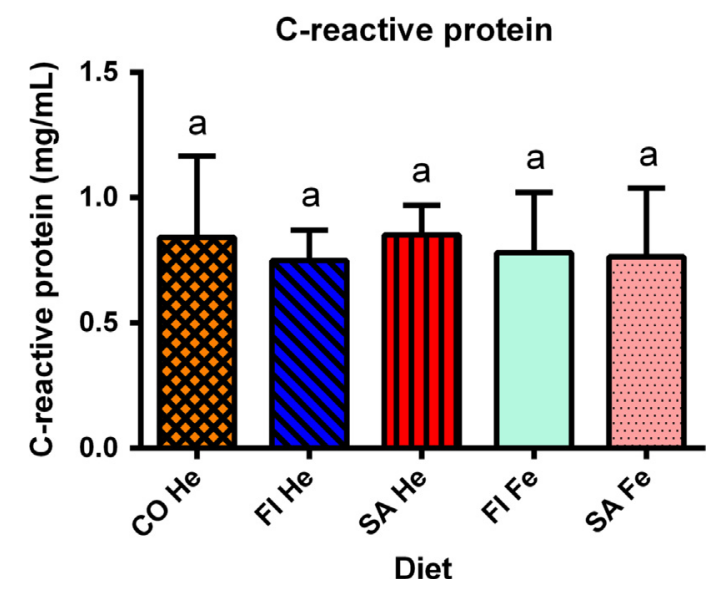

Fig. 4. C-reactive protein in rat plasma. $\mathrm{CO} \mathrm{He}$, hydrogenated coconut oil/hemin diet; FI He, fish oil/hemin diet; SA He, safflower/hemin diet; FI Fe; fish oil/ferric citrate diet; SA Fe; safflower/ferric citrate diet. The same letter between groups shows no significant statistical differences. $n=6$ animals.

\section{HNE-his adducts}

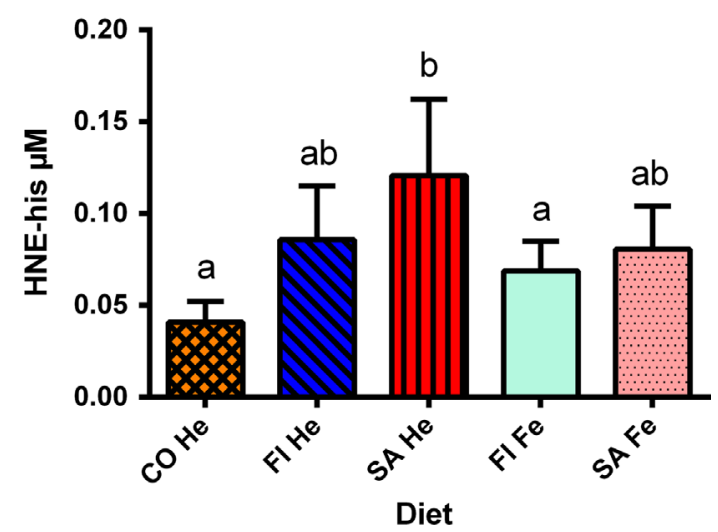

Fig. 5. HNE-histidine protein adducts in rat liver. $\mathrm{CO} \mathrm{He}$, hydrogenated coconut oil/ hemin diet; FI He, fish oil/hemin diet; SA He, safflower/hemin diet; FI Fe; fish oil/ ferric citrate diet; SA Fe; safflower/ferric citrate diet. Different letters between groups show significant statistical differences with at least $P<0.05 . n=6$ animals.

In order to study the consequences of heme iron and PUFA-rich diets in terms of potential toxicity in relation to colorectal cancer development, we performed additional in vitro experiments using 
conditionally immortalized mouse colon epithelial cells and a mouse rectum carcinoma cell line (CMT93). The cells were exposed to sterilized fecal waters collected from the rats that had received the different diets. At the same time, we have measured the concentration of TBARS in those fecal extracts and in the different diets (Fig. 6).

Fish oil with both forms of iron as well as safflower oil combined to heme iron in diet had a pronounced cytotoxic effect on both cell lines exposed to the respective fecal waters, while safflower oil combined to ferric citrate or heme iron combined to coconut oil had no deleterious effect. In parallel, the respective TBARS content was very high in the fecal water of rats fed a diet with fish oil/hemin and was less increased in the case of safflower oil/hemin and fish oil/ferric citrate diets if compared to safflower oil/ferric citrate or to coconut oil/hemin diets. We observed a similar TBARS profile in the diets, except that coconut oil/hemin diet presented less TBARS than safflower oil/ferric citrate one.

\section{Discussion}

The major aim of our study was to point out that most urinary lipid peroxidation/oxidative stress biomarkers are dependent on the diet, mostly on its lipid nature, and especially in the presence of iron in the heminic form that is believed to have more efficient catalytic properties toward lipid oxidation. For this purpose, we used unsaturated oils that are prone to oxidation, but from different types representing the precursors of the lipid oxidation biomarkers that we wanted to test, namely $\omega-6$ fatty acids for HNE/DHN-MA, and fatty acids with more than two double bonds

Table 2

Liver fatty acid composition of the rats fed the different diets for 17 days.

\begin{tabular}{|c|c|c|c|c|c|}
\hline & $\mathrm{CO} \mathrm{He}$ & FI He & SA He & FI Fe & SA Fe \\
\hline SFA & $49.5 \pm 2.1^{a}$ & $49.7 \pm 1.9^{\mathrm{a}}$ & $48.1 \pm 2.5^{a}$ & $49.6 \pm 1.3^{a}$ & $50.6 \pm 2.1^{a}$ \\
\hline MUFA & $37.3 \pm 3.2^{a}$ & $22.7 \pm 2.4^{b}$ & $17.2 \pm 1.2^{c}$ & $22.1 \pm 1.4^{b}$ & $27.8 \pm 4.0^{\mathrm{d}}$ \\
\hline PUFA & $13.2 \pm 2.2^{\mathrm{a}}$ & $27.6 \pm 2.1^{b}$ & $34.7 \pm 2.1^{c}$ & $28.3 \pm 2.1^{b}$ & $21.6 \pm 2.9^{d}$ \\
\hline$\sum \omega-6$ & $10.5 \pm 1.8^{a}$ & $15.4 \pm 1.5^{b}$ & $30.0 \pm 1.9^{c}$ & $9.4 \pm 1.1^{\mathrm{a}}$ & $20.0 \pm 2.6^{\mathrm{d}}$ \\
\hline$\Sigma \omega-3$ & $2.7 \pm 0.4^{a}$ & $12.2 \pm 1.2^{b}$ & $4.7 \pm 0.6^{c}$ & $19.0 \pm 1.0^{\mathrm{d}}$ & $1.6 \pm 0.3^{\mathrm{e}}$ \\
\hline DBI & $91.7 \pm 7.9^{\mathrm{a}}$ & $147.3 \pm 8.7^{b}$ & $153.1 \pm 9.7^{b}$ & $159.0 \pm 7.1^{b}$ & $102.8 \pm 7.2^{a}$ \\
\hline $20: 4 n-6$ & $6.6 \pm 1.3^{a}$ & $10.5 \pm 1.0^{b}$ & $17.5 \pm 1.5^{\mathrm{c}}$ & $5.9 \pm 0.7^{\mathrm{a}, \mathrm{d}}$ & $8.4 \pm 1.4^{\mathrm{a}, \mathrm{e}}$ \\
\hline MDA prec. & $11 \pm 2.3^{a}$ & $24.0 \pm 1.2^{b}$ & $27.2 \pm 2.2^{\mathrm{c}}$ & $25.6 \pm 1.5^{b, c}$ & $13.3 \pm 2.1^{a}$ \\
\hline
\end{tabular}

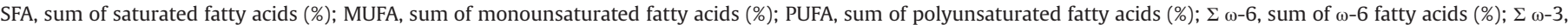

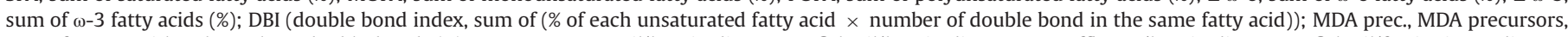

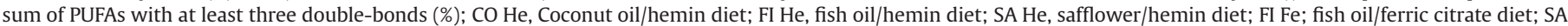
Fe; safflower/ferric citrate diet. Different letters between groups show significant statistical differences with at least $P<0.05$. $n=6$ animals.
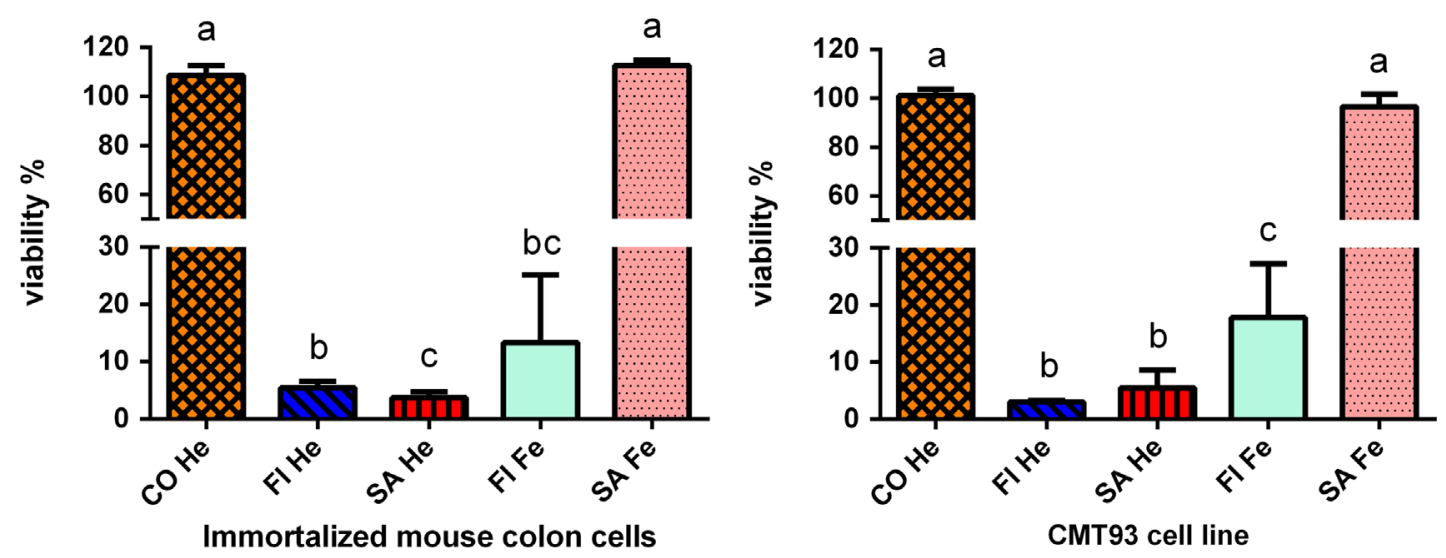

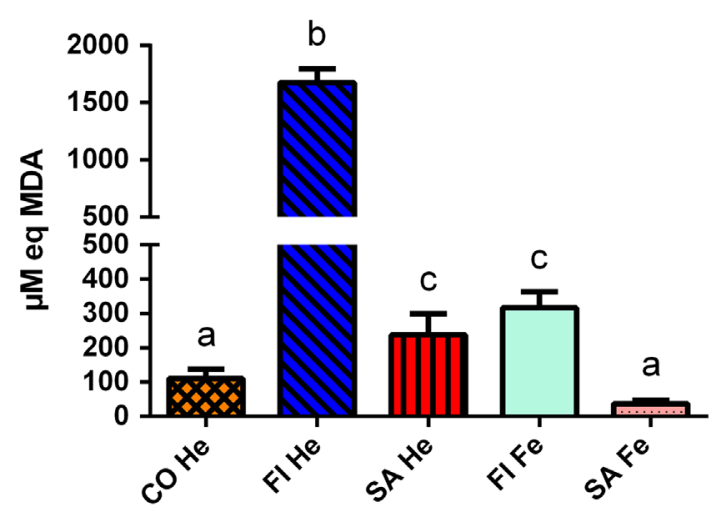

TBARS in fecal waters

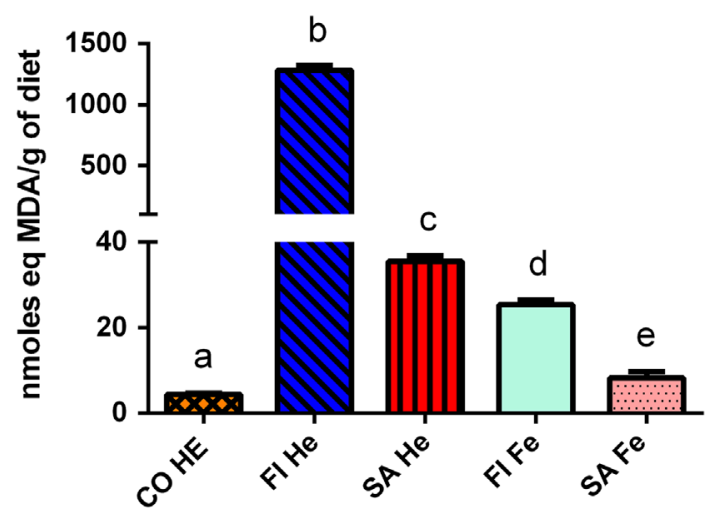

TBARS in diets

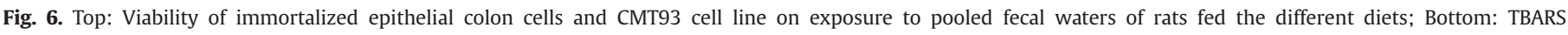

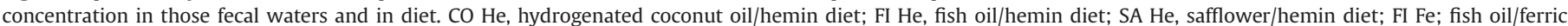
citrate diet; SA Fe; safflower/ferric citrate diet. Different letters between groups show significant statistical differences with at least $P<0.05$ (6 replicates). 
for MDA. In addition, we aimed to show that the situation was rather different for 8-iso- $\mathrm{PGF}_{2 \alpha}$ because its unique precursor was hardly found in diet. So we used the $\omega$-6-rich safflower oil as an HNE/DHN-MA provider and the long-chain unsaturated fish oil as MDA provider. The results obtained in the present study highlight the importance of the presence of heme iron together with the type of dietary oil, in the formation of secondary lipid oxidation products that are well known as oxidative stress biomarkers. The urinary excretion of DHN-MA and MDA strongly depended on the type of oil used in diets. This was expected since MDA comes from the peroxidation of PUFAs that bear at least three double bonds, while HNE and its major urinary metabolite DHN-MA are generated through peroxidation of fatty acids of the $\omega-6$ family. Therefore, $5 \%$ dietary fish oil, containing long-chain polyunsaturated fatty acids, increased dramatically MDA excretion while 5\% safflower oil, containing mainly linoleic acid, increased dramatically DHN-MA excretion. It is important to note that $5 \%$ is an amount that is conventionally used for rodent diets. These increases were even more important when these oils were associated with iron in its heminic form, although iron concentration was the same as in ferric citrate diets. The hemin concentration we used in the diets was in the range of a possible human consumption. Interestingly, this effect of heme iron disappeared when heme iron was combined to a saturated oil that provided no precursor for lipid peroxidation, highlighting the prominent role of heme iron as an oxidation catalyst.

Heme iron has been reported to be a very effective catalyst of lipid peroxidation $[35,36]$. In a previous work, the urinary excretion of MDA, DHN-MA, and 8-iso-PGF $2 \alpha$ was measured before and after treatment of rats with $\mathrm{BrCCl}_{3}$, a well-known inducer of lipid peroxidation in the liver. Such a treatment resulted in a 3-fold increase of urinary excretion for DHN-MA and 8-iso-PGF $2 \alpha$ and a 5-fold increase for MDA, $48 \mathrm{~h}$ following the treatment. Thus, we concluded that all three biomarkers reflected the $\mathrm{BrCCl}_{3}$-induced liver lipid peroxidation in a similar manner [10]. In the present study, the increase in MDA or DHN-MA urinary excretion due to the experimental diet was much more important than the one observed previously with $\mathrm{BrCCl}_{3}$. To be sure that this increase was mainly due to lipid peroxidation occurring in diet or in intestinal lumen during digestion, several points were checked.

First, as the diets could provoke intestinal inflammation due to the presence of irritant lipid peroxidation products, as shown by fecal TBARS assay (Fig. 6), colonic MPO assay was performed and revealed an increased colonic inflammatory process with heme iron/PUFA diets, compared to the safflower oil/ferric citrate or to the coconut oil/heme iron ones. This inflammation could be due to microbiota modification. Indeed, IJssennagger et al. have observed a modification of microbiota of mice after a heme-rich diet [37]. These authors simultaneously investigated the effects of dietary heme on colonic microbiota and on colon mucosa of mice. They observed that heme iron increased Bacteroidetes and decreased Firmicutes in colonic contents. This shift was observed with a Westernized diet ( $40 \%$ fat (mainly palm oil), low calcium (30 $\mu \mathrm{mol} / \mathrm{g}$ ) supplemented with $0.5 \mu \mathrm{mol} / \mathrm{g}$ heme iron) and was most likely caused by a selective susceptibility of Gram-positive bacteria to heme cytotoxic fecal water, which is not observed for Gram-negative bacteria, allowing expansion of the latter. However, these authors did not show any appreciable immune response detected in the heme-fed mice, nor modification of inflammation pathways. Interestingly, in the present study, we reported no cytotoxicity of fecal waters from rats fed heme iron and the saturated coconut oil. So, we think that the increase in MPO is mainly due to lipid peroxidation, as reflected by the fecal TBARS assay. However, this increase in MPO activity, high with a fish oil/ hemin diet and moderate with a safflower oil/hemin, did not parallel the urinary excretion of any of the biomarkers tested here.
Nevertheless, we may assume that such a moderate inflammation in the colon probably contributed to the formation of MDA and DHN-MA, but certainly not to such extent to explain the effect of diets on their urinary excretion.

On the other hand, as diet could change the composition of cellular membrane fatty acids and subsequently provide more precursors for endogenous lipid peroxidation, the liver fatty acid composition was used as an indicator of fatty acid status of the animals in this study. The increase in urinary MDA, however, did not reflect an increased cellular formation due to a modification of membrane fatty acids, as the proportion of fatty acids in liver that are precursors of MDA (i.e., bearing at least three double bonds) were not more pronounced in rats given fish oil than in rats given safflower oil. Opposite to that, the pattern of DHN-MA excretion followed the proportion of $\omega-6$ fatty acids in the liver that indicated more $\omega-6$ fatty acids with safflower oil than with fish oil and, interestingly, more $\omega-6$ fatty acids with heme iron than with ferric citrate. We can conclude accordingly, that at least a small amount of this urinary DHN-MA could come from the higher amount of cellular $\omega-6$ fatty acid undergoing basal lipid peroxidation and further HNE formation, as was also shown by the increased presence of HNE-His protein adducts in animals fed a safflower and heme iron diet. Since HNE is mostly generated during oxidation of linoleic and arachidonic acid, and since this particular diet group had the highest levels of $\omega-6$ and $20: 4 n-6$, it is logical that the same animals had also the highest levels of HNEHis adducts. It should be also noted that HNE-His adducts are considered as relatively stable modifications of various proteins, that might affect essential biological processes of proliferation, differentiation, and apoptosis, while in liver they might be associated with both nonviral hepatitis, cirrhosis, and carcinogenesis $[38,39]$.

However, it seems reasonable to think that this increase in MDA and DHN-MA was mainly due to formation in diet or during digestion, as reflected by TBARS measured in fecal extracts and in diet. In a recent study, Larsson et al. [40] reported the huge formation of TBARS in an in vitro simulated gastrointestinal digestion after addition of heme iron, in the form of hemoglobin, to a cod liver oil emulsion, rich in $\omega$-3 PUFAs, while Kanner's group reported that the human stomach was a suitable medium for lipid peroxidation, especially in the presence of red meat [41]. With the current study we confirmed these findings, in an animal model, with an original comparison of two forms of dietary iron, while we have to stress that the effect of dietary heme iron on the proportion of $\omega-6$ fatty acids in the liver has never been reported before. We think that the formation of lipid oxidation products occurred in diet and during digestion because we have shown that HNE given to rats orally was hardly found in the distal part of the intestine, indicating absorption of this compound in the upper parts of the intestine (unpublished results). In parallel, when a hemin/safflower oil or a hemin/fish oil diet is given to rats, significant amounts of HNE/HHE are found in the fecal extracts, this with two different mass spectrometry methods (article in preparation). Taken together, those results indicate that there is a luminal formation of those lipid oxidation products during digestion, after consumption of a hemin/safflower or fish oil diet, because most of the lipid oxidation products present in diet are absorbed before reaching the distal parts of the intestine.

The case of 8 -iso- PGF $_{2 \alpha}$ is somehow different because its urinary excretion was increased only by a 1.5 - and 5 -fold factor with fish oil- and safflower oil hemin-rich diet, respectively, compared to respective ferric citrate diets. This increase was similar to the one observed after $\mathrm{BrCCl}_{3}$ treatment in our previous study [10]. The unique precursor of 8 -iso- $\mathrm{PGF}_{2 \alpha}$ is arachidonic acid [42], which is absent in safflower oil and generally in common plant oils and is found in very little quantities in fish oils. In the 
present study, the formation of 8 -iso- $\mathrm{PGF}_{2 \alpha}$ was very limited in diet, or during digestion. The differences observed in urinary 8-iso-PGF ${ }_{2 \alpha}$ excretion should then be due to either an inflammatory process or an important modification of tissue fatty acids leading to an increase of arachidonic acid in tissues, which would be also be utilized as a source of endogenous HNE production, in particular under circumstances of oxidative stress. 8-iso- $\mathrm{PGF}_{2 \alpha}$ urinary excretion did not mirror the differences observed in MPO activity, so we assume that inflammation was not a major pathophysiological process generating 8 -iso- $\mathrm{PGF}_{2 \alpha}$ in the case of the diets used. On the other hand, it reflected quite well the proportion of arachidonic acid found in the liver, so it is reasonable to assume that even if both processes contributed to 8 -iso- $\mathrm{PGF}_{2 \alpha}$ urinary excretion, the colonic inflammation was moderate enough, as confirmed by the absence of modification of the plasmatic concentration of C-reactive protein, to be blurred by the effect on tissue fatty acid composition.

It is noteworthy that meat contains arachidonic acid either in tissue membranes, particularly in poultry meat, or in "visible" fat that could give dietary formation of 8 -iso- PGF $_{2 \alpha}$ [43]. However, this may be very limited as we previously showed that rats fed meat-containing diets (60\% freeze-dried chicken or beef) did not undergo any increase in 8-iso- $\mathrm{PGF}_{2 \alpha}$ urinary excretion [14]. Moreover, Halliwell's group reported that the diet contribution of 8-iso$\mathrm{PGF}_{2 \alpha}$ after a single meal would not influence its plasma concentration in humans [44]. But these studies did not note a possible long-term effect of $\omega$ - 6 fatty acid-rich diets through modification of tissue fatty acid composition as a source of precursors for endogenous 8-iso- PGF $_{2 \alpha}$ formation.

As a result of the data obtained in the present study, urinary MDA and DHN-MA should be used cautiously as systemic lipid peroxidation/oxidative stress biomarkers, and only under conditions in which food consumption is carefully controlled, because both compounds are formed on precursors that can be found in diet. Opposite to that, urinary 8 -iso- $\mathrm{PGF}_{2 \alpha}$ might be considered as a "golden standard" biomarker reflecting systemic lipid peroxidation/oxidative stress, because this compound may be formed only in very small quantities on lipid peroxidation in diet. However, it is important to keep in mind that an indirect effect of diet could not be ruled out, through modification of the fatty acid proportions in tissue membranes, particularly of arachidonic acid. The increase in urinary excretion we showed in the present study with a safflower oil/heme iron diet is in the same range as the one observed after a strong inducer of liver lipid peroxidation [10].

In this work, we observed an important increase of TBARS, reflecting dietary aldehydes deriving from lipid peroxidation as MDA and perhaps also HNE, in fecal extracts with heme iron diets compared to ferric citrate ones (around 5-fold increase). This important effect of the heminic form of iron on the formation of these secondary oxidation products can be explained by a high catalytic efficiency of heme in lipid peroxidation of PUFAs as explained above. Thus, the maximal luminal TBARS formation occurred with a fish oil/hemin diet in which there is an efficient lipid peroxidation catalyst together with the highest double bond index. Heme iron is present in high concentration in red meat, causing lipid peroxidation [45]. Red and processed meats are the only foodstuffs considered as a convincing cause of colorectal cancer by the World Cancer Research Fund panel [46]. Heme iron could explain the epidemiological link existing between red meat and processed meat consumption and colorectal cancer risk. We showed here that fecal extracts from rats fed a diet containing heme iron and PUFAs were more toxic to epithelial colon cells than fecal extracts from rats fed on diets containing ferric citrate or on a diet containing heme iron but no PUFAs. It is worth noting that recent in vitro experiments using an artificial gut model revealed that HNE, present in heme iron-rich foodstuffs [15], can increase permeability of the intestinal barrier [47], which could further increase absorption of deleterious compounds, including lipid oxidation products, from the gut.

Usually, fish oil and its $\omega-3$ PUFAs are associated with beneficial health effects, due to their anti-inflammatory, antiproliferative, proapoptotic properties and their role in cell immune functions. Concerning cancer, fish oil and $\omega-3$ fatty acids are believed to have preventive and adjuvant therapeutic properties [48]. However, epidemiological studies of colorectal cancer show conflicting results and meta-analyses on prospective cohort studies showed no or a very weak protective effect of fish or $\omega$-3 fatty acid consumption [49-51]. The effect of $\omega-3$ fatty acids could reflect their indirect and mild anti-inflammatory effect, due to competition of eicosapentaenoic acid (EPA) with arachidonic acid for the enzymatic production of eicosanoids which have anti-inflammatory or pro-inflammatory properties, depending on their precursor [52]. Furthermore, $\omega$-3 PUFAs are also known to modify cell membrane composition and fluidity and particularly lipid raft composition, which are related to cancer [53]. However, $\omega-3$ PUFAs are unstable and prone to oxidation [54] and this fact should be considered with respect to lipid peroxidation toxic end-product formation. Moreover, in an in vivo study on mice, Awada et al. showed an increase in plasma inflammation markers with a high-fat diet with oxidized $\omega-3$ PUFAs and an accumulation of 4-hydroxyhexenal, the $\omega-3$ PUFA specific lipid oxidation product in blood [55]. To our knowledge, there were no in vivo studies of $\omega-3$ PUFAs combined with the presence of heme iron into diet in rodent models. When heme iron is present, the dramatically enhanced luminal formation of potentially cytotoxic and genotoxic lipid oxidation products that we observed in the present study could counterbalance the beneficial effects of $\omega-3$ fatty acids. It is noteworthy that fecal extracts from fish oil diet-fed rats have cytotoxic properties on colon epithelial cells, even in the absence of heme iron. We have observed that 4-hydroxyhexenal, the $\omega-3$ PUFA specific lipid oxidation product, had the same cytotoxic, genotoxic, and "selective toward preneoplastic cells" properties as HNE on epithelial colon cells [56]. Taken together, these facts could provide an explanation for the rather disappointing and conflicting effects of dietary $\omega-3$ PUFA observed in epidemiological studies, in which the heme iron consumption is not taken into account. In conclusion, the risk associated with the simultaneous intake of very-long-chain unsaturated fatty acids and heme iron, as myoglobin-rich fishes (tunas) or as "omega3" dietary complements together with a red meat-rich diet, should be reconsidered. Accordingly, we suggest that extensive rodent and other in vivo carcinogenesis studies be carried out to make sure that a diet containing fish oil plus heme iron does not promote colorectal cancer.

\section{Acknowledgments}

Support by the EU Grant COST B35 and the French/Croatian Program COGITO is kindly acknowledged. We thank Florence Blas$y$-Estrada for taking good care of the animals and Denis Corpet for reviewing the manuscript.

\section{References}

[1] Casós, K.; Zaragozá, M. C.; Zarkovic, N.; Zarkovic, K.; Andrisic, L.; Portero-Otín, M.; Cacabelos, D.; Mitjavila, M. T. A fish-oil-rich diet reduces vascular oxidative stress in apoE(-/-) mice. Free Radic. Res. 44:821-829; 2010.

[2] Esterbauer, H. Schaur, R. J.: Zollner, H. Chemistry and biochemistry of 4-hydroxynonenal, malonaldehyde and related aldehydes. Free Radic. Biol. Med. 11:81-128; 1991.

[3] Dhanakoti, S. N.; Draper, H. H. Response of urinary malondialdehyde to factors that stimulate lipid peroxidation in vivo. Lipids 22:643-646; 1987.

[4] Babu, M. S.; Bobby, Z.; Habeebullah, S. Increased inflammatory response and imbalance in blood and urinary oxidant-antioxidant status in South Indian women with gestational hypertension and preeclampsia. Clin. Biochem. 45:835-838; 2012 
[5] Gomes, P.; Simão, S.; Silva, E.; Pinto, V.; Amaral, J. S.; Afonso, J.; Serrão, M. P.; Pinho, M. J.; Soares-da-Silva, P. Aging increases oxidative stress and renal expression of oxidant and antioxidant enzymes that are associated with an increased trend in systolic blood pressure. Oxid. Med. Cell. Longev. 2:138-$145 ; 2009$.

[6] Bae, S.; Pan, X. -C.; Kim, S. -Y.; Park, K.; Kim, Y. -H.; Kim, H.; Hong, Y. -C. Exposures to particulate matter and polycyclic aromatic hydrocarbons and oxidative stress in schoolchildren. Environ. Health Perspect. 118:579-583; 2010.

[7] Sirota, R.; Gorelik, S.; Harris, R.; Kohen, R.; Kanner, J. Coffee polyphenols protect human plasma from postprandial carbonyl modifications. Mol. Nutr. Food Res. 57:916-919; 2013.

[8] Gorelik, S.; Ligumsky, M.; Kohen, R.; Kanner, J. A novel function of red wine polyphenols in humans: prevention of absorption of cytotoxic lipid peroxidation products. FASEB J. 22:41-46; 2008.

[9] Zarkovic, N. 4-Hydroxynonenal as a bioactive marker of pathophysiological processes. Mol. Aspects Med. 24:281-291; 2003.

[10] Peiro, G.; Alary, J.; Cravedi, J. -P.; Rathahao, E.; Steghens, J. -P.; Guéraud, F. Dihydroxynonene mercapturic acid, a urinary metabolite of 4-hydroxynonenal, as a biomarker of lipid peroxidation. BioFactors 24:89-96; 2005.

[11] Kuiper, H. C.; Miranda, C. L.; Sowell, J. D.; Stevens, J. F. Mercapturic acid conjugates of 4-hydroxy-2-nonenal and 4-oxo-2-nonenal metabolites are in vivo markers of oxidative stress. J. Biol. Chem. 283:17131-17138; 2008.

[12] Kuiper, H. C.; Bruno, R. S.; Traber, M. G.; Stevens, J. F. Vitamin C supplementation lowers urinary levels of 4-hydroperoxy-2-nonenal metabolites in humans. Free Radic. Biol. Med. 50:848-853; 2011.

[13] Pierre, F.; Santarelli, R.; Taché, S.; Guéraud, F.; Corpet, D. E. Beef meat promotion of dimethylhydrazine-induced colorectal carcinogenesis biomarkers is suppressed by dietary calcium. Br. J. Nutr. 99:1000-1006; 2008.

[14] Pierre, F.; Peiro, G.; Taché, S.; Cross, A. J.; Bingham, S. A.; Gasc, N.; Gottardi, G.; Corpet, D. E.; Guéraud, F. New marker of colon cancer risk associated with heme intake: 1,4-dihydroxynonane mercapturic acid. Cancer Epidemiol. Biomark. Prev. 15:2274-2279; 2006.

[15] Gasc, N.; Taché, S.; Rathahao, E.; Bertrand-Michel, J.; Roques, V.; Guéraud, F. 4-hydroxynonenal in foodstuffs: heme concentration, fatty acid composition and freeze-drying are determining factors. Redox Rep. 12:40-44; 2007.

[16] Seppanen, C. M.; Csallany, A. S. Incorporation of the toxic aldehyde 4-hydroxy2-trans-nonenal into food fried in thermally oxidized soybean oil. J. Am. Oil Chem. Soc. 81:1137-1141; 2004.

[17] Seppanen, C. M.; Csallany, A. S. Formation of 4-hydroxynonenal, a toxic aldehyde, in soybean oil at frying temperature. J. Am. Oil Chem. Soc. 79:1033-1038; 2002.

[18] Roberts, L. J.; Morrow, J. D. Measurement of F(2)-isoprostanes as an index of oxidative stress in vivo. Free Radic. Biol. Med. 28:505-513; 2000.

[19] Zarković, N.; Zarković, K.; Schaur, R. J.; Stolc, S.; Schlag, G.; Redl, H.; Waeg, G.; Borović, S.; Loncarić, I.; Jurić, G.; Hlavka, V. 4-Hydroxynonenal as a second messenger of free radicals and growth modifying factor. Life Sci. 65: 1901-1904; 1999.

[20] Pierre, F.; Taché, S.; Petit, C. R.; Van der Meer, R.; Corpet, D. E. Meat and cancer: haemoglobin and haemin in a low-calcium diet promote colorectal carcinogenesis at the aberrant crypt stage in rats. Carcinogenesis 24:1683-1690; 2003.

[21] Pierre, F.; Freeman, A.; Taché, S.; Van der Meer, R.; Corpet, D. E. Beef meat and blood sausage promote the formation of azoxymethane-induced mucin-depleted foci and aberrant crypt foci in rat colons. J. Nutr. 134:2711-2716; 2004.

[22] Pierre, F.; Tache, S.; Guéraud, F.; Rerole, A. L.; Jourdan, M. -L.; Petit, C. Apc mutation induces resistance of colonic cells to lipoperoxide-triggered apoptosis induced by faecal water from haem-fed rats. Carcinogenesis 28:321-327; 2007.

[23] Van Der Meer-Van Kraaij, C.; Van Lieshout, E. M. M.; Kramer, E.; Van Der Meer, R.; Keijer, J. Mucosal pentraxin (Mptx), a novel rat gene 10-fold down-regulated in colon by dietary heme. FASEB J. 17:1277-1285; 2003.

[24] Sesink, A. L.; Termont, D. S.; Kleibeuker, J. H.; Van der Meer, R. Red meat and colon cancer: the cytotoxic and hyperproliferative effects of dietary heme. Cancer Res. 59:5704-5709; 1999.

[25] Steghens, J. P.; van Kappel, A. L.; Denis, I.; Collombel, C. Diaminonaphtalene, a new highly specific reagent for HPLC-UV measurement of total and free malondialdehyde in human plasma or serum. Free Radic. Biol. Med. 31: 242-249; 2001.

[26] Guéraud, F.; Peiro, G.; Bernard, H.; Alary, J.; Créminon, C.; Debrauwer, L.; Rathahao, E.; Drumare, M. -F.; Canlet, C.; Wal, J. -M.; Bories, G. Enzyme immunoassay for a urinary metabolite of 4-hydroxynonenal as a marker of lipid peroxidation. Free Radic. Biol. Med. 40:54-62; 2006.

[27] Pradelles, P.; Grassi, J.; Maclouf, J. Enzyme immunoassays of eicosanoids using acetylcholine esterase as label: an alternative to radioimmunoassay. Anal. Chem. 57:1170-1173; 1985.

[28] Wang, Z.; Ciabattoni, G.; Créminon, C.; Lawson, J.; Fitzgerald, G. A.; Patrono, C.; Maclouf, J. Immunological characterization of urinary 8-epi-prostaglandin F2 alpha excretion in man. J. Pharmacol. Exp. Ther. 275:94-100; 1995.

[29] Folch, J.; Lees, M.; Sloane Stanley, G. H. A simple method for the isolation and purification of total lipides from animal tissues. J. Biol. Chem. 226:497-509; 1957.

[30] Borovic, S.; Rabuzin, F.; Waeg, G.; Zarkovic, N. Enzyme-linked immunosorbent assay for 4-hydroxynonenal-histidine conjugates. Free Radic. Res. 40:809-820; 2006.
[31] Waeg, G.; Dimsity, G.; Esterbauer, H. Monoclonal antibodies for detection of 4-hydroxynonenal modified proteins. Free Radic. Res. 25:149-159; 1996.

[32] Bradley, P. P.; Priebat, D. A.; Christensen, R. D.; Rothstein, G. Measurement of cutaneous inflammation: estimation of neutrophil content with an enzyme marker. J. Invest. Dermatol. 78:206-209; 1982.

[33] Ohkawa, H.; Ohishi, N.; Yagi, K. Assay for lipid peroxides in animal tissues by thiobarbituric acid reaction. Anal. Biochem. 95:351-358; 1979.

[34] Forest, V.; Clement, M.; Pierre, F.; Meflah, K.; Menanteau, J. Butyrate restores motile function and actin cytoskeletal network integrity in apc mutated mouse colon epithelial cells. Nutr. Cancer 45:84-92; 2003.

[35] Lorrain, B.; Dangles, O.; Loonis, M.; Armand, M.; Dufour, C. Dietary ironinitiated lipid oxidation and its inhibition by polyphenols in gastric conditions. J. Agric. Food Chem. 60:9074-9081; 2012.

[36] Roginsky, V.; Zheltukhina, G. A.; Nebolsin, V. E. Efficacy of metmyoglobin and hemin as a catalyst of lipid peroxidation determined by using a new testing system. J. Agric. Food Chem. 55:6798-6806; 2007.

[37] IJssennagger, N.; Derrien, M.; van Doorn, G. M.; Rijnierse, A.; van den Bogert, B.; Müller, M.; Dekker, J.; Kleerebezem, M.; van der Meer, R. Dietary heme alters microbiota and mucosa of mouse colon without functional changes in hostmicrobe cross-talk. PloS One 7:e49868; 2012.

[38] Marquez-Quiñones, A.; Cipak, A.; Zarkovic, K.; Fattel-Fazenda, S.; Villa-Treviño, S. Waeg, G.; Zarkovic, N.; Guéraud, F. HNE-protein adducts formation in different precarcinogenic stages of hepatitis in LEC rats. Free Radic. Res. 44:119-127; 2010.

[39] Zarkovic, N.; Cipak, A.; Jaganjac, M.; Borovic, S.; Zarkovic, K. Pathophysiological relevance of aldehydic protein modifications. J. Proteomics 92:239-247; 2013.

[40] Larsson, K.; Cavonius, L.; Alminger, M.; Undeland, I. Oxidation of cod liver oil during gastrointestinal in vitro digestion. J. Agric. Food Chem. 60:7556-7564; 2012.

[41] Kanner, J.; Lapidot, T. The stomach as a bioreactor: dietary lipid peroxidation in the gastric fluid and the effects of plant-derived antioxidants. Free Radic. Biol. Med. 31:1388-1395; 2001.

[42] Morrow, J. D.; Hill, K. E.; Burk, R. F.; Nammour, T. M.; Badr, K. F.; Roberts 2nd L. J. A series of prostaglandin F2-like compounds are produced in vivo in humans by a non-cyclooxygenase, free radical-catalyzed mechanism. Proc. Natl. Acad. Sci. USA 87:9383-9387; 1990.

[43] Li, D.; Ng, A.; Mann, N. J.; Sinclair, A. J. Contribution of meat fat to dietary arachidonic acid. Lipids 33:437-440; 1998.

[44] Gopaul, N. K.; Halliwell, B.; Anggård, E. E. Measurement of plasma F2isoprostanes as an index of lipid peroxidation does not appear to be confounded by diet. Free Radic. Res. 33:115-127; 2000.

[45] Kanner, J. Oxidative processes in meat and meat products: quality implications. Meat Sci. 36:169-189; 1994.

[46] World Cancer Research Fund. WCRF. Food, nutrition, physical activity, and the prevention of cancer: a global perspective. Washington, DC: World Cancer Research Fund and American Institute for Cancer Research; 2007.

[47] Cindric, M.; Cipak, A.; Zapletal, E.; Jaganjac, M.; Milkovic, L.; Waeg, G.; Stolc, S.; Zarkovic, N.; Sunjic Borovic, S. Stobadine attenuates impairment of an intestinal barrier model caused by 4-hydroxynonenal. Toxicol. In Vitro 27:426-432; 2013.

[48] Merendino, N.; Costantini, L.; Manzi, L.; Molinari, R.; D’Eliseo, D.; Velotti, F. Dietary $\omega-3$ polyunsaturated fatty acid DHA: a potential adjuvant in the treatment of cancer. BioMed Res. Int. 2013/310186; 2013.

[49] MacLean, C. H.; Newberry, S. J.; Mojica, W. A.; Khanna, P.; Issa, A. M.; Suttorp, M. J.; Lim, Y. -W.; Traina, S. B.; Hilton, L.; Garland, R.; Morton, S. C. Effects of omega-3 fatty acids on cancer risk: a systematic review. J. Am. Med. Assoc. 295:403-415; 2006.

[50] Geelen, A.; Schouten, J. M.; Kamphuis, C.; Stam, B. E.; Burema, J.; Renkema, J. M. S.; Bakker, E. -J.; van't Veer, P.; Kampman, E. Fish consumption, n-3 fatty acids, and colorectal cancer: a meta-analysis of prospective cohort studies. Am. J. Epidemiol. 166:1116-1125; 2007.

[51] Gerber, M. Omega-3 fatty acids and cancers: a systematic update review of epidemiological studies. Br. J. Nutr. 107(Suppl. 2):S228-S239; 2012.

[52] Calder, P. C. n-3 polyunsaturated fatty acids, inflammation, and inflammatory diseases. Am. J. Clin. Nutr. 83:1505S-1519S; 2006.

[53] Turk, H. F.; Chapkin, R. S. Membrane lipid raft organization is uniquely modified by n-3 polyunsaturated fatty acids. Prostaglandins Leukot. Essent. Fatty Acids 88:43-47; 2013.

[54] Dyall, S. C. Methodological issues and inconsistencies in the field of omega-3 fatty acids research. Prostaglandins Leukot. Essent. Fatty Acids 85:281-285; 2011.

[55] Awada, M.; Soulage, C. O.; Meynier, A.; Debard, C.; Plaisancié, P.; Benoit, B.; Picard, G.; Loizon, E.; Chauvin, M. -A.; Estienne, M.; Peretti, N.; Guichardant, M.; Lagarde, M.; Genot, C.; Michalski, M. -C. Dietary oxidized n-3 PUFA induce oxidative stress and inflammation: role of intestinal absorption of 4-HHE and reactivity in intestinal cells. J. Lipid Res. 53:2069-2080; 2012.

[56] Bastide, N.; Chenni, F.; Audebert, M.; Santarelli, R.; Tache, S.; Naud, N.; Baradat, M.; Jouanin, I.; Surya, R.; Hobbs, D. A.; Kuhnle, G. G.; Raymond-Letron, I.; Gueraud, F.; Corpet, D.; Pierre, F. A central role for heme iron in colon carcinogenesis associated with red meat intake. Cancer Res. 75:870-879; 2015. 